\title{
O Jongo: Voz, Ritmo, MemóRIa E TRAnSmissão
}

Renata Mattos Avril ${ }^{1}$

\section{Resumo}

O jongo, como manifestação cultural, social e artística, apresenta-se como um espaço vivo e contínuo de (re)criação da representação identitária da cultura afrobrasileira, transmitindo em sua prática uma história de resistência e inscrição de alteridade que se atualiza no estabelecimentos de laços sociais. Nestes laços, abrese, pela via estética - que pode ser lida como uma via política - a possibilidade de convivência das diferenças e de releituras e transformações daquilo que é transmitido. O jongo pode, assim, ser tomado como ponto de criação de um novo em torno da memória social e do objeto voz.

PALAVRAS-ChAVE: Jongo, voz, memória, alteridade, resistência

\footnotetext{
${ }^{1}$ Psicanalista, com Pós-doutorado pela Universidade de Nice Sophia-Antipolis, Doutora em Pesquisa e Clínica em Psicanálise pela Universidade do Estado do Rio de Janeiro. Investiga especialmente a articulação entre psicanálise e música a partir do objeto voz. Endereço postal: Mas Calmettes 66200 Elne França. E-mail: renatamattosavril@yahoo.fr
} 
Vem pro jongo,

Ô vem jongueiro ver, João-Congo,

$\mathrm{O}$ jongo tem que ter

Mais um herdeiro

Nesse terreiro

Pro jongo não morrer.

Sérgio Santos e Paulo César Pinheiro

\begin{abstract}
Por aqui andou o café e com ele a riqueza material, mas ficou com os negros
\end{abstract} velhos a riqueza musical do jongo.

Alceu Mayard Araújo

A memória e a prática do jongo, transformadas em patrimônio cultural, vêm desempenhando papel importante neste acerto de contas com o passado que abre caminhos para o futuro.

Hebe Mattos e Martha Abreu

Há alguns anos atrás, um amigo violonista francês, que conheceu o jongo através da música homônima de Paulo Belinatti, se surpreendeu ao saber que isso que ele sabia ser uma tradição que chegou em nosso país em sua origem, com a escravização, se mantém viva e pulsante até hoje. Para além de um traço de nossa cultura, de um ritmo que se escuta e que se apresenta inscrito em nossa música, o jongo tem ainda hoje uma bela e importante função cultural e social no coração de comunidades brasileiras, especialmente comunidades afro-brasileiras rurais do sudeste, sem que isso as isole. Ao contrário, o jongo é simultaneamente uma forma de cultivar continuamente raízes, reavivando-as, e de fazê-las florescer, podendo assim ser compartilhadas.

Longe de ser uma simples desinformação, como rapidamente se poderia supor, o espanto desse músico francês aponta para uma dimensão de surpresa, de ruptura e enlaçamento com o cotidiano que o próprio jongo evoca. Ruptura com a cultura dominante que buscava silenciar - e ainda hoje busca, o que é inaceitável - as expressões socioculturais negras, a ligação com a terra de origem da qual inúmeros grupos e comunidades foram brutalmente separados. Ruptura com a dor e o trabalho escravo, e enlaçamento da própria cultura com o novo cotidiano, com a comunidade que daí se originava e que renascia, com voz, a cada vez que o jongo era tocado, entoado, cantado e dançado. $O$ jongo torna viva e ativa a voz de grupos e de pessoas que não se deixaram silenciar. E que continuam a musicar, a invocar a dança e, por elas, a resistência. 
Tendo morado no Rio de Janeiro, desde muito nova tive em diversos momentos a chance de ver meu dia mudar ao me deparar com uma roda de jongo em algum lugar na cidade, quebrando o ritmo das ruas, entre as pessoas e passantes, entre curiosos, apreciadores, jongueiros, sobretudo, e aqueles que não conseguem dizer não ao convite que tal música faz, respondendo com o corpo balançando, dançando, rodando, cantando, batendo palmas, mexendo pés. Sim, é surpreendente que uma dança de resistência, de celebração do passado e do presente voltados para o futuro, de uma expressividade rítmica e narrativa tão imponente, se mantenha viva, apesar de ter passado por significativas transformações. O que indica mesmo sua potência transformadora e seu caráter de transmissão em ressonância com uma plasticidade em dialogar com cada nova geração e tempo que se estabelecem a partir dela mesma.

A surpresa que aí se encontra é, de fato, apenas aparente, sendo a permanência e os desdobramentos do jongo frutos de uma conquista, de uma luta das comunidades remanescentes de quilombolas no sudeste brasileiro que garantiu e inscreveu a efetivação de um espaço de expressão da cultura afro-brasileira. Desde 2005, o jongo é reconhecido como patrimônio imaterial do Brasil pelo Instituto do Patrimônio Histórico e Artístico Nacional (IPHAN), tendo sido registrado no Livro das Formas de Expressão.

O jongo, como manifestação cultural, social e artística, apresenta-se como um espaço vivo e contínuo de (re)criação da representação identitária da cultura afrobrasileira, transmitindo em sua prática uma história de resistência e inscrição de alteridade que se atualiza no estabelecimentos de laços sociais. Nestes laços, abrese, pela via estética - que pode ser lida como uma via política - a possibilidade de convivência das diferenças e de releituras e transformações daquilo que é transmitido, sendo assim tomado como ponto de criação de um novo. No caso do jongo, são notórios os desdobramentos tanto rítmico-musicais quanto de organizações em comunidades distintas que dele se efetuaram, presentificando assim a cultura e promovendo um laço entre memória e experiência atual.

Tomado como um dos precursores do samba, na contemporaneidade a expressão da música e da dança do jongo propicia uma ressignificação das relações sociais que constituíram sua base, evocando e referenciando a ancestralidade, e igualmente a presença do sagrado e do religioso na comunidade. Dos exemplos mais notórios de resignificação da cultura do jongo, encontramos no Rio de Janeiro o Jongo 
da Serrinha, cujo trabalho de Mestre Darcy, falecido em 2001, promoveu uma releitura e recriação desta dança/canto/ritmo/expressão/poética a partir da performance, do jongo como espetáculo que mantém viva a tradição e convida a integração de novos valores culturais.

A música assim (re)efetua o entrelaçamento entre individual e coletivo, eu e outro, sagrado e profano, passado e presente, dentre outras relações dialéticas. Da musicalidade que constitui e invoca a fala e a expressão de cada sujeito à criação musical que singulariza um grupo, possibilitando a construção de sua discursividade e a transmissão de seus traços, marcas e memória. É este o percurso que aqui propomos, tomando como foco central o jongo e sua história. Mais que isso, procuraremos nos ater à estrutura rítmica e musical do jongo, enfocando ainda a dimensão de construção narrativa através da poesia, do canto e do improviso, bem como da dança e da participação da audiência nesse processo.

Como interlocutor, privilegio aqui a psicanálise freudiana e lacaniana, destacando nelas a importância da função da voz e do ritmo na emergência do sujeito face aos demais e em como, na criação musical, tais elementos se articulam dando a ouvir uma resposta simultaneamente singular e plural daquele que a cunha. É pela voz, entendida aqui como imaterial, como voz Outra que invoca uma voz própria, que um sujeito pode emergir a partir dos processos subjetivos de alienação e separação, e para a instauração da memória e da historicidade, ou seja, da possibilidade de contar e recontar. Esses processos nunca são de todo definitivos, convidando a novos movimentos de corte e separação, dos quais a arte pode se prestar a promovê-los e mesmo a convocá-los.

Pode o jongo ser entendido, nesta perspectiva, como um espaço coletivo de elaboração, criação e transmissão de uma voz singular? Como então pensar o caráter de alienação e separação dentro de uma coletividade, encaminhando-se para uma construção simbólica, imaginária e real que é transmitida e reatualizada pela expressão artística? Com estes pontos, caminharemos e dançaremos.

\section{JONGO: RITMO, DANÇA}


O jongo, igualmente conhecido no sudeste brasileiro sob os nomes de caxambu, tambu e tambor, é uma expressão que traz viva em si a história de povos africanos que foram trazidos para o Brasil como escravos, principalmente os de idioma bantu, de Angola. Com caráter fortemente rural, o jongo, no demasiadamente longo e inaceitável período da escravização no Brasil, apresentava aos seus criadores/participantes um espaço de convivência e de expressão no qual havia uma torção ente cotidiano/celebração, profano/sagrado, passado/futuro, especialmente na transmissão oral das culturas que o originaram e na improvisação musical que integrava os fatos presentes da comunidade.

O que o jongo apresenta em sua música, sua dança e sua narrativa poética, seus pontos, seus passos de dança, seus tambores, suas tradições, lança questões tanto em relação à estrutura de sua criação quanto à sua função dentro de cada grupo no qual ele se insere e é vivido. Nas tramas do que ele assim apresenta, encontra-se um caráter enigmático que faz a transmissão de uma história particular. Uma primeira tentativa de caminharmos aqui, colhendo pistas quanto a esse enigma, compare pelo dossiê realizado pelo IPHAN sobre o Jongo no Sudeste:

\begin{abstract}
Forma de expressão afro-brasileira, o jongo integra percussão de tambores, dança coletiva e práticas de magia. Acontece nos quintais das periferias urbanas e de algumas comunidades rurais do Sudeste brasileiro, assim como nas festas dos santos católicos e divindades afro-brasileiras, nas festas juninas, no Divino e no 13 de maio da abolição dos escravos. O jongo é uma forma de louvação aos antepassados, consolidação de tradições e afirmação de identidades. Ele tem raízes nos saberes, ritos e crenças dos povos africanos, principalmente os de língua bantu. São sugestivos dessas origens o profundo respeito aos ancestrais, a valorização dos enigmas cantados e o elemento coreográfico da umbigada. No Brasil, o jongo se consolidou entre os escravos que trabalhavam nas lavouras de café e cana-de-açúcar, no Sudeste brasileiro, principalmente no vale do rio Paraíba do Sul. Nos tempos da escravidão, a poesia metafórica do jongo permitiu que os praticantes da dança se comunicassem por meio de pontos que os capatazes e senhores não conseguiam compreender. Sempre esteve, assim, em uma dimensão marginal, em que os negros falam de si, de sua comunidade, por meio da crônica e da linguagem cifrada (BRASIL, 2007, p. 14).
\end{abstract}

Ciframento este que comparece tanto na estrutura formal da música e da poesia cantada/improvisada, quanto na dança e mesmo na dinâmica social que se forma em torno desta expressão coletiva. Se tomamos o aspecto da dança, a disposição do grupo em roda, que, aos pares, nela entra, não sem antes saudar os tambores e músicos, já se mostra reveladora do que ali está em jogo: 
Os jongueiros se dispõem numa roda, alternando-se homens e mulheres, quando o número assim o permite. Os instrumentistas, em linha, tocam o círculo como uma secante. Inicia-se a dança. A roda gira em direção contrária à dos ponteiros do relógio e os dançadores, fazendo um balancê de 2 ou 3 passos, se viram à direita e à esquerda. Não se abraçam, mas semelham apenas fazer, e, ao final dos balancês, trocam mesuras (RIBEIRO, 1984, p. 11).

Igualmente os instrumentos musicais anunciam pistas do que se coloca como espaço de preservação de laços não apenas com a ancestralidade e com as regras sociais estabelecidas no comum, mas com o aspecto de sacralidade. Os tambores, metáfora da voz divina e das entidades religiosas, geralmente são em número de dois ou três, sendo feitos de madeira e couro animal e chamados os maiores de angoma ou tabu e os menores de candogueiro. E são acompanhados pelo guaiá e pela puíta, instrumentos percussivos próximos ao que mais comumente conhecemos como chocalho e cuíca.

Tradicionalmente, faz parte ainda da dinâmica do jongo a presença da fogueira, cuja função se destina principalmente a conservar a voz dos instrumentos em suas sonoridades:

Junto ao terreiro do jongo arde uma grande fogueira. Destina-se de modo especial, à conservação da sonoridade dos tambores. Quando sua voz enfraquece, os tocadores aproximam-se com eles do fogaréu. Carinhosamente, umedecem o couro com pinga e, devagarinho, vão batendo, experimentando com as pontas dos dedos, até que a pele aquecida se retesa e Ihes dá o timbre perfeito. Ali se esquentam os jongueiros quando desce a friagem nas longas noites de inverno (Ibid; p. 14).

Ainda, o canto do jongo se dá pela forma de pontos, versos poéticos, muitas vezes improvisados, cantados por um solista e em coro, que costuma marcar o ritmo dos pontos batendo palmas, juntamente com os participantes que circundam a roda. Atualmente, porém, muitas comunidades se utilizam de pontos já estabelecidos, ficando, com isso, esvaecida a importância do improviso e da consequente inclusão de acontecimentos do cotidiano mais recente. Noutras, isso se acentua por um certo "afastamento" das raízes mais tradicionais do jongo, construindo a partir de seus elementos o que se convencionou chamar de "jongo espetáculo", no qual há um deslocamento de traços mais "antigos" e característicos do período de sua criação no Brasil, no período da escravização, ocorrendo uma reinvenção de si.

E podemos ler tal reinvenção como uma via de fazer com a voz dessa cultura de modo a ser transmitida, reverberando e ressoando na multiplicidade cultural 
brasileira. Voz de resistência e de renovação. Para avançarmos em direção a este aspecto, trago a seguir algumas pontuações sobre a voz e a memória na psicanálise com o intuito de pensar a história e os elementos primordiais do jongo como uma via de delimitação da cultura jongueira e ressignificação dela mesma reenlaçando, a partir de sua singularidade e alteridade, uma possibilidade de troca e diálogo polifônico com o campo do social.

\section{Voz, Alteridade E Memória: O Sujeito E Os Laços Com O Outro}

A questão da voz para a psicanálise se apresenta como de fundamental importância na constituição do sujeito face à alteridade mais radical a ele, o Outro, e em relação a como ele pode responder ao que lhe chega como enigma sobre si mesmo a partir daí. A voz faz corpo, sujeito, faz falar. Ela o faz pela convocação da pulsão invocante, "a mais próxima da experiência do inconsciente", segundo Lacan (1964/1998, p. 102), alertando que se trata nesse nível do desejo do Outro. É por ele que podemos nos tornar sujeitos; pela incorporação da voz.

Para tanto, é preciso aceitar o convite do Outro para entrar na linguagem, lhe dizer sim e não, cunhando um ponto de surdez a esta voz presente e enigmática para dela se separar. Behajung e Austossung, segundo as coordenadas de Freud (1925/2006, p. 249-258). Alienação e separação, de acordo com Lacan (1964/1998). Continuidade e escansão, ambos operados também pela voz, ainda que a função de corte não seja unicamente a ela atribuída. O corte é atribuído ao objeto a em todas as suas incidências possíveis: seio, fezes, falo, olhar e voz. A voz surge, nessa operação de separação, como litoral entre sujeito e Outro, na medida em que estes são simultaneamente constituídos.

Para Freud (1950[1895]/2006, p. 323-446), o sujeito somente pode surgir através dos cuidados maternos (por alguém que incarna a função materna, é preciso sublinhar) na medida em que eles possibilitam ao pequeno vivente sair de seu estado de prematuridade e, conforme aprendemos com Lacan, entrar na linguagem, organizando-se psiquicamente, ainda que se exclua simultaneamente um objeto real, das Ding. Tais cuidados não são feitos sem a dimensão da sonoridade e, mais ainda, 
da musicalidade da fala e da voz da mãe ${ }^{2}$ na convocação ao infans para que este advenha como sujeito do inconsciente. A mãe dá ao bebê um testemunho de que se pode ao ouvir a voz do Outro, aceitar seu convite à subjetivação e torná-la inaudita pelo recalque originário.

É necessário que haja um momento inicial de fusão com o outro, seu semelhante, no caso, a mãe ou aquele que assumirá tal função de cuidador e encarnará o Outro. Esta fusão deverá chegar ao fim para que um sujeito surja. É preciso, pois, fazer um corte que faz emergir os campos do sujeito, do Outro e do objeto, na dimensão da falta. Esse corte incide também no contínuo da voz material do bebê. A emissão da voz deste, voz material, vibração das cordas vocais, precisa ganhar uma outro estatuto, de imaterialidade, de perda, para que os significantes que ela traz em si - palavras e músicas - possam ser posteriormente ditos pela fala ou criados pela via musical, poética ou artística.

São os intervalos na voz que separam os corpos da mãe e do bebê, produzindo um primeiro laço com o Outro, operando como primeiro organizador no psiquismo. Nesta medida, como sustenta Catão (2009, p. 224), "a voz faz litoral”, ou seja, ela promove a separação e simultânea constituição dos campos heterogêneos do real, do impossível de simbolizar, e do simbólico, articulando-os. A voz promove uma organização inicial do sujeito no simbólico a partir do real do corpo.

A mãe, assim, terá a importante função de envolver o bebê, pela continuidade de suas vogais, chamando-o para a linguagem, tal qual fazem as sereias em seu canto, mas também efetuar uma ruptura neste laço, pelo corte das consoantes, sem o qual seu canto seria mortífero. O que faz tal corte é mais propriamente a dimensão da voz do pai (igualmente compreendido aqui como função, função paterna) que é passado pela voz musicada e desejante da mãe.

Se a voz é resto da operação de separação do sujeito no campo do Outro, caberá ao falante dar a ela algum destino, seja ele estrutural (ou seja, na delimitação das estruturas clínicas, neurose, perversão ou psicose), ou mesmo contingente e a posteriori (como no contorno e desvelamento de seu vazio no fazer artístico). A pulsão invocante, em seu circuito, exige que o sujeito efetue um movimento de ouvir, ser ouvido e de se fazer ouvir. Isso passando pelo corpo, pela estrutura de borda da zona

\footnotetext{
${ }^{2}$ Aqui, novamente - e a cada vez que este temo aparecer -, nos referimos à mãe como aquela/e que incarnará e transmitirá a função materna para o sujeito.
} 
erógena que a ela se relaciona, e pelo campo do Outro, ouvido a voz deste e dele se separando. Tal pulsão é aquela que invoca o sujeito falante, trazendo ao mesmo tempo, além do ouvir, um chamar, como nos indica Vivès (2009, p. 329-341).

A voz é assim uma "voz que procura a voz", como coloca Alencar (1997, p. 354), uma voz que tem um endereçamento, que procura uma resposta do Outro, por ter efetuado o ato de se fazer surdo à voz deste pelo recalque originário. Todavia, tal resposta nunca virá. É nessa medida que a música pode comparecer dando a ouvir uma resposta possível diante do impossível de se obter uma resposta do Outro, e que ela faz trazendo, cifradamente, algo sobre a posição singular de um sujeito para com este objeto e pode dar a ouvir igualmente algo sobre a posição de quem por ela é tocado.

A voz faz corte no que era contínuo, criando, simultaneamente, ritmo e tempo pela alternância presença/ausência. É preciso, deste modo, haver uma marcação significante da voz no infans para que, pela pausa, pela escansão da voz, se cave o vazio deste objeto. Neste sentido, a voz precisa ser perdida, precisa cair do corpo do sujeito, marcando um vazio. Com isso, Lacan (1962-63/2005, p. 301) demarca que a voz deve ser incorporada, o que de dá "uma função que serve de modelo para nosso vazio". Vazio este que o sujeito porta e que diz também de um vazio no Outro, já que "é próprio da estrutura do Outro constituir um certo vazio, o vazio de sua falta de garantia (Ibid; , p. 300)".

Quanto à memória, é igualmente pelo início do movimento desejante e com voz que há a possibilidade de um sujeito se contar e contar sua história, a partir daquilo que nele se inscreve. Na Carta 52, datada de 6 de dezembro de 1896, Freud apresenta uma hipótese sobre o psiquismo em termos que se aproximam ao tratamento de uma linguagem ao falar da "tradução" de traços entre os diferentes registros psíquicos. Aborda a inscrição de traços mnêmicos que precisariam passar pela transcrição e pela retranscrição de tempos em tempos, o que o leva a afirmar "que a memória não se faz presente de uma só vez, mas se desdobra em vários tempos; que ela é registrada em diferentes espécies de indicações (FREUD, 1950[1986]/1990, p. 324)".

O inconsciente, assim, se apresenta pela simultaneidade de traços inscritos, cujos arranjos se dão a posteriori. Também no artigo freudiano Uma nota sobre "o bloco mágico", podemos observar a ideia do psiquismo como um aparelho de memória 
no qual há a inscrição de traços em diferentes níveis. Seria pela própria inscrição dos traços mnêmicos, com suas posteriores transcrições e retranscrições que o funcionamento do psiquismo se instalaria. Neste processo, a voz instaura um ritmo singular, um modo particular de lidar e fazer com a memória, permitindo, com isso, uma narração e uma transmissão.

Podemos, então, concluir que a voz é um objeto que promove a separação entre sujeito e Outro e que é na medida em que, pelo recalque originário, o sujeito cria um ponto de surdez em relação à voz do Outro que o circuito da pulsão invocante pode passar de um ouvir a um ser ouvido e, por fim, um se fazer ouvir. Há uma perda do contínuo da voz que instaura, pela falta, um descontínuo. A voz torna-se inaudita e é enquanto ausência que ela é contornada no circuito pulsional. Neste sentido, quando a voz encontra-se inaudita, o Outro não responde ao enigmático “Que vuoi?”, "Que queres?". Caberá ao próprio sujeito cunhar uma resposta singular ao desejo do Outro. E podemos ouvir na música uma via de responder a esta questão que apresenta uma criação mediada pelo simbólico frente ao vazio real da ausência do objeto voz.

Lembro aqui o que Miller afirma sobre o que criamos em torno da voz e a função disto para os sujeitos:

Se falamos tanto, se fazemos nossos colóquios, nossos charlatanismos, se cantamos e escutamos os cantores, se fazemos música e se a escutamos, a tese de Lacan, segundo meu ponto de vista, comporta que tudo isso é feito para fazer calar aquilo que merece chamar-se a voz como objeto a (MILLER, 1997, p. 17).

A música, ao nos oferecer um meio de lidar com o imprevisível da voz, faz com que seu vazio seja garantido ao ser contornado.

\section{TRANSMISSÃo E INVOCAÇÃo: MUSICAR E DANÇAR}

Partindo dos parâmetros acima apresentados, proponho um paralelo entre, de um lado, a constituição do sujeito a partir da voz e da possibilidade de criação da memória a partir daí, e, de outro, a construção e transmissão de uma tradição enquanto memória viva de um grupo a partir da expressão rítmica e musical. De modo similar ao sujeito, também no coletivo a separação e a criação de uma singularidade face ao Outro e aos outros se dão pelo corte em um contínuo alienante que faz, com 
isso, uma delimitação de um conjunto que se mantém pelas inscrições de um ou mais traços em comum. É com a voz, pela voz, pelo timbre único desta voz se lançando na cultura, que grupos sociais distintos podem se construir e trocar entre si.

Escutando a história e a manifestação do jongo, é possível formular como hipótese que a voz faz aí, simultaneamente, função de criação de uma singularidade, de uma identidade coletiva, e, mais ainda, de resistência pela via da transmissão poética de sua tradição e expressividade. Metafórica e cifradamente trazendo elementos ímpares de uma cultura forçada brutalmente a se distanciar de seu berço, o jongo faz com que seja a ela possível não apenas se recriar no lugar ao qual foi lançada, mais principalmente criar novos pontos de discursividade e representação, de circulação e reapropriacão de um comum. Entre passos de danças e pontos musicados.

Transmitir a invocação da voz e a memória inscrita e a se renovar no presentefuturo através da poética rítmica de um grupo. A oralidade do jongo, com seus pontos, batuques, que convidam a um dançar ético diante da própria história, alinhavando passado, presente e futuro, se renova e faz avançar a dimensão de coletividade singular face à alteridade social sem, com isso, promover um isolamento ou fechamento. É no sentido de um contorno das identidades, da memória, do fazer coletivo, mesmo da celebração coletiva de uma história, que o jongo se direciona, portando em si uma abertura tanto ao que a ele é diferente quanto a possibilidade de inclusão e criação de um novo como processo de um desdobramento de seu ritmo singular.

Musicar e dançar podem, assim, ser lidos como equivalentes a uma escrita das tradições vivificadas pela transmissão da voz que se fez singular das comunidades em que o jongo se apresenta como marca, como traço expressivo e ético. 


\section{REFERÊNCIAS}

ALENCAR, M. L. O. de A. Da voz à música: o grão e o resto. In: Os destinos da pulsão: sintoma e sublimação / Kalimeros - Escola Brasileira de Psicanálise. Rio de Janeiro: Contra Capa Livraria, 1997.

BRASIL. Jongo no Sudeste. Brasília, DF: Iphan, 2007.

CATÃO, I. O bebê nasce pela boca: voz, sujeito e clínica do autismo. São Paulo: Instituto Langage, 2009.

FREUD, S. (1950[1895]) Proyecto de psicología. In: Obras Completas, vol. I. Buenos Aires: Amorrortu Editores, 2006.

FREUD, S. (1950[1986]) Extratos dos documentos dirigidos a Fliess - Carta 52. In: Edição Standard Brasileira das Obras Psicológicas Completas de Sigmund Freud,vol. I. $3^{\mathrm{a}}$ Ed. Rio de Janeiro: Imago, 1990.

FREUD, S. (1925) La negación. In: Obras Completas, vol. XIX. Buenos Aires: Amorrortu Editores, 2006.

LACAN, J. (1964) O Seminário, Livro 11 - Os quatro conceitos fundamentais da psicanálise. $2^{\mathrm{a}}$ ed. Rio de Janeiro: Jorge Zahar Ed., 1998.

LACAN, J. (1962-1963) O Seminário, Livro 10 - A angústia. Rio de Janeiro: Jorge Zahar Editor, 2005.

MILLER, J.-A. Jacques Lacan y la voz. In: Freudiana - Publicación de la Escuela Europea de Psicoanálisis de Catalunya, $n$. 21. España: Ediciones Paidós, 1997.

RIBEIRO, M. de L. B. O jongo. Rio de Janeiro: FUNARTE, 1984.

VIVÈS, J.-M. Para introduzir a questão da pulsão invocante. In: Rev. Latinoam. Psicopat. Fund., São Paulo, v. 12, n. 2, 2009. 


\section{Jongo: Voice, Rhythm, MEMORY AND TRANSmission}

\section{ABSTRACT}

The jongo, as a cultural, social and artistic manifestation, can be understood as a living and continuous space of (re)creation of the identity representation of the AfroBrazilian culture, transmitting by its practice a history of resistance and of inscription of the otherness, which is actualized in the installation of social bonds. These bonds, through a aesthetic way that can be read as a political way, open the possibility of coexistence of differences and the reinterpretations and transformations of what is transmitted. The jongo can thus be taken as the point of creation of something new though the social memory and the voice object.

KEYWORDS: Jongo. Voice. Memory. Otherness. Resistance 


\section{Jongo : VoIX, Rythme, Memoire Et Transmission}

\section{RÉSUMÉ}

Le jongo, en tant que manifestation culturelle, sociale et artistique, se montre comme un espace vivant et continu de (ré)création de la représentation identitaire de la culture afro-brésilienne, tout en transmettant dans sa pratique une histoire de résistance et d'inscription de l'altérité qui s'actualise dans l'établissement de liens sociaux. Par ces liens, à partir d'une voie esthétique qui peut être lue comme une voie politique, il est ouvert la possibilité de coexistence des différences, ainsi que de relectures et transformations de ce qui est transmis. Le jongo peut ainsi être compris comme un point de création de un nouveau autour de la mémoire sociale et de l'objet voix.

MotS-CLÉS: Jongo. Voix. Mémoire. Altérité. Résistance 
RECEBIDO EM 26/09/2020

APROVADO EM 10/10/2020

C 2020 Psicanálise \& Barroco em revista

http://www.seer.unirio.br/index.php/psicanalise-barroco/index revista@psicanaliseebarroco.pro.br

Programa de Pós-Graduação em Memória Social — UNIRIO

Memória, Subjetividade e Criação

www.memoriasocial.pro.br/proposta-area.php 